\title{
Six fragments of a theory of translation as understanding
}

\author{
Wolfgang Kubin ${ }^{1,2}$
}

Received: 21 August 2020 / Accepted: 9 November 2020 / Published online: 5 March 2021

(C) The Author(s) 2021

\begin{abstract}
Against the common view of translation as the translation of a text or an author the article argues there is not such a thing. Any translation has its basis in the (subjective) understanding of the translator who only translates according to one's own comprehension. So there is no loyal translation in the sense of "word-for-word" (Wortwörtlichkeit). It is also an error to think editions are reliable and dictionaries offer a kind of complete vocabulary. So what a translation can do is to open up a wide range of possibilities. The only norm is the logic of understanding an author and a text. Thus individual understanding and individual translating are the two sides of one coin.
\end{abstract}

Keywords Literal translation · Word · Sense/meaning · Editions · Dictionaries · Free translators $\cdot$ Understanding $\cdot$ Communication $\cdot$ Hermeneutics $\cdot$ Possibilities

Even our gestures are different-the gesture of Mercy, of contempt for understanding -All I ask you for is understanding Zbigniew Herbert: To Yehuda Amichaj

By now, the twentieth century is recognized to be central in the development of modern concepts of understanding and translation. Actually, both items should be regarded as one and the same, because we translate only what we suppose to understand, and understanding is a kind of translation in the sense that simply speaking we have to transport (Latin: transferre) something from the "other" to "ourselves" or vice versa. In other words, we have to bring something "home": as messengers for

Wolfgang Kubin

kubin@uni-bonn.de

1 Bonn University, Bonn, Germany

2 Shantou University, Shantou, China 
others or as enrichment for ourselves. Despite the fact that the theory of "self" and "other" after more than thirty years is a little bit outdated by now, because it is much more complicated than can be blindly taken for granted, it still seems to be a possible starting point here for our theoretical undertaking.

Though international translation theory has been extremely developed in recent decades, it has not yet really helped to pave the ground for a better knowledge of the process of rendering in Chinese Studies and in countries like China and USA which did not much promote our business until recently.

True, there are many voices nowadays which preach a way of better understanding of China through translation work, so that one can talk at the same time of a kind of a fury of understanding (Verstehenswut) and a fury of translation (Übersetzungsfieber), but as soon as it comes to the judgement of translators we are still told the same old stories by our readers or even colleagues: Translators are traitors, no translation can be perfect, translators are parrots, they are parasites, translation is no creation, everyone can translate, this guy or that lady is only a translator, translation is the second earliest profession after prostitution etc. We are used to hear things like these even at universities, be they in America, China or in Germany. But still worse might be the fact that our names are very often not mentioned at all. I experience this every morning when I listen to the reading of a foreign poem or to the review of a foreign book broadcasted by the radio station WDR III (West German Radio Programme No. III).

So, better not to translate? Is it better not to help one's own people to understand China through translation?

\section{The trouble with the word}

It was in the fall of 2018 that the poet Yang Lian (b. 1955) and his wife, the novelist Liu Youyou (Yo Yo), were enjoying a stroll with me on the beautiful campus of Shantou University. We talked about translation. All of a sudden Yo Yo said: "What's that all about? Translating is so easy, you just check a dictionary for a Chinese word and then write it down in German." Hearing this, I was disappointed. Did she forget how difficult it was for me to translate the poetry of her husband who claims to make use of a language of his own that he calls Yanglish? How would it be possible to find a counterpart of it in any reference book?

Moreover, what is a word? In German or English, it seems to be clear, but in Chinese? All that specialists can tell us is what a character is and means, but as soon as there seems to pop up a binomial or a combination of more than two characters in a text, even linguists feel helpless. Fensterbrett makes one single word in German, the same goes for windowsill in English, but window ledge means two words. And what about chuangtaibanr 窗台板儿? One word? Two, three or four words? Chuang tai ban er? Finally, what about "Triumphbogen", the German equivalent for French "Arc de Triomphe"? Three words instead of one word?

The literary critic Rainald Simon (b. 1951) prefers using the idea of "the word" as a means for reviewing German translations of Chinese literature. Recently he criticized the new and first complete translation of the novel The Three Kingdoms 
(Sanguo Yanyi) by Eva Schestag (Luo 2017). He accused her of having delivered an incomplete work, because she-so his view-deleted words and sentences of the original deliberately. Thus the announcement of a first complete translation by the publishing house would be incorrect. Our Frankfurt sinologist still sticks to the oldfashioned illusion of some kind of literal translation which demands the rendering of almost every word (Wort für Wort). But nowadays any theoretician or practical person knows that doing so amounts to ruining the text. One has to detach oneself from the original in order to produce something new and lively. This is why a critic has to judge the entire book, not a single word, not one sentence or a section or chapter, in this case all of more than 1700 pages!

\section{What do we translate?}

I do not want to go deeper into the details here. There is something more important. Without knowing it, Rainald Simon left us with a big problem: What is a word, a single word that he asks us translators to translate as a single word and not as part of a sentence, section or chapter? What he aims for is called "Wortwörtlichkeit" in German, which actually is different from the English version "word-for-word" as recommended by German-English dictionaries. Behind this outdated theory, which is still so common in Chinese studies, lurks the illusion that a word has only one sound and one meaning. One sound in German? We can go with it. One sound in Chinese? That is impossible, because the majority of Chinese characters might have not only different tones (sisheng: four tones in Mandarin), but also different pronunciations. See for instance common characters as 教: jiāo, jiào or 参: cān, cēen, shēn. Without paying attention to the characters before and after, we can neither know the tone nor the pronunciation nor the meaning! All these things are not in the characters themselves; they are exclusively in our mind! They have to be taught to us! And if we run into a Southerner, a Cantonese, we shall run into even greater confusion, because what we get to hear is any kind of mess, everything seems to be wrong, the nine tones, the grammar, the vocabulary in comparison with Putonghua (Mandarin).

We can see something similar in German. "Innovation", "revolution", "impression" at the beginning of a sentence can be French, English or German! The pronunciation is always different. How do we, however, know how to read these words? We have to leave them alone and have a look around what the context provides.

We can also find something similar in one and the same language system, for instance in German. It has to do with the phenomenon of emphasis. German words never let you know where to lay emphasis upon. You have to know through the praxis of listening and speaking. Here we are with some examples which need the context in order to become unambiguous:

A word as "August" can be read as Augúst (English Áugust!) or Áugust (personal name for a man). "Nobel" might be nóbel (noble) or Nobél (Nobel Prize), "modern" is either modérn (modern) or módern (to rot), "Heroin" is alternatively Heroín (heroin) or Heróin (female hero), and finally "Tenor" can be interpreted as Tenór (tenor) or Ténor (tenor). 
The indication is not in the words themselves, we have to consider the words before and after! Thus, it is totally impossible to translate a word as a word. There is always something more or something in between which I shall show in a while.

And even more important: Chinese characters never have only one single meaning that they can be forced into, but because of their long history of thousands of years, they unfold so many different meanings that it is sometimes impossible to decide what a character perhaps might have meant at all. Therefore, as the theory of modern philosophy goes: a "word" offers its meaning through its use. And the use is bound to a sentence, respectively linked to its context ("Wort [...]" 2004).

All in all, and from the point of philosophers, there is no fixed term for the "word", a word itself does not mean anything, it is only within the frame of a sentence that it receives a certain meaning. Here's a very simple example in German language. It is a kind of joke and makes only use of one single word which changes its meaning all the time. This single word has to be understood as a sentence and the listener or reader has necessarily to supply words for any understanding.

Morgen!
Morgen!

Haben Sie Kohlen?

Morgen!

Morgen?

Morgen!

Morgen!

Morgen!

"Morgen" is "morning" or "tomorrow" in English. In order to understand in any language, we have to supply. Two persons are meeting in a shop for coal. The customer starts the dialogue, the shopkeeper answers. We are not told so, we must already know or guess.

Good morning!

Good Morning!

Do you have a lump of coal?

Not before tomorrow!

Tomorrow for sure?

Certainly, tomorrow!

I wish you a good morning!

So do I! 


\section{Editions and dictionaries}

The reason why I often tell my students to throw their dictionaries away is that a dictionary only might show us a certain direction we might tend to, but not the richness of any language. It is restricted to a certain amount of vocabulary, it shows us merely a small piece of possibilities. Even the new German Duden (2020) with its 148.000 entries of German words lets us nurture false hopes. Though it added 3000 new words, it cancelled at the same time 300, among them are Fernsprechapparat (telephone), Bäckerjunge (baker's boy) and Niethose (German for jeans), words I grew up with. This indicates that even the Duden cannot provide us with a complete Germany vocabulary!

So what do we translate when we translate? We do not translate a word, we translate the sense of a sentence, of a section, of a chapter. Whose understanding is that? It is our understanding, not the so-called meaning of the original.

Why not? Is it not our dream to reproduce in our mother tongue what an author, a text seems to tell its readers? Yes, that is our dream, but it is an illusion. We can never really know what is in a book or what is on the mind of a writer. When Johann Georg Hamann (1730-1788) declares God is a writer, too, do we dare to say we understand the "word" of God which is not a single word, but the "script", the Bible? As we cannot claim to comprehend a being higher than us, we can only interpret and transfer our understanding. So we have not only been interpreting, i.e. translating the Bible for "two thousand" years, but also the Daode Jing which can be regarded as a holy script, too, therefore we have never stopped translating and explaining it until hitherto.

As the oeuvres of Friedrich Hölderlin (1770-1843) or Cao Xueqin (1715?-1763?) show, there is not such a thing as a complete edition that we can blindly trust, there are only many different editions at our hands that we can believe in or not. That is one of the many reasons why any translation is not only an interpretation, but also a kind of decision in many aspects. This is true up till today. We can never take any publication for granted. It might be changed by the publishing house for what reason so ever. The author might have rewritten it all the time or belies us when asking questions. There are a lot of striking examples which I will refrain from mentioning here because I have already talked about these matters in several articles.

\section{"Free" translation, even more free translator}

In recent years, and under the influence of French and German philosophy, translation theories have liberated translators from the task of making themselves the slave of an author or a certain book. We are now declared to be free. Free for misunderstanding, misinterpretation, wrong translation? No, the case is much more complicated as it seems to be.

The readers, they are dreamers, they assume when reading our product they are not reading us, but the so called real creator. But all they hold in hands is our work, our language, our understanding, our view, our decision. We are not empathetic, we are cruel! We have the right to cut! We do not translate every word, every sentence, and 
every section! We cut according to our comprehension, because we see a text clearer than an author. An author is not a sacred person, rather forgettable, unreliable, without much knowledge of one's own doing. Ask a writer: What do you mean here and there? And one will get the following answer very often: I myself do not know either!

So, a translator is free to "rewrite" what is in front of the eyes. And what is in front of our eyes on a page does not belong to the writer any more. As soon as being finished a text becomes independent and open one for anyone. The author has lost the right of last authority. We are allowed to do what we want to, but it must have its logic. When requested to explain why we must be able to explain for what reason we did this and not that. Even the obviously most self-understood question, namely the problem of loyalty (Treue, 信 xin), is open (offen). We translators are expected to be loyal both to the text and to the producer, but up till now it seems that no one ever reflected upon the topic of loyalty! Who am I loyal to? To a corrupt text as the one of Mo $\mathrm{Zi} \mathrm{(479-381)?} \mathrm{To} \mathrm{the} \mathrm{poor} \mathrm{language} \mathrm{of} \mathrm{a} \mathrm{contemporary} \mathrm{Chinese} \mathrm{writer?} \mathrm{To}$ all the mistakes an author can produce? To the publisher who demands to cut a book to half of it? To the readership which wants light entertainment? Or are we loyal to ourselves? To our morals, to our intelligence, to our insight, to our high standard of mother tongue?

Among well-educated and well-equipped translators worthy of this designation, the aspect of wrong or right to judge a translation no longer exists. Our only criteria are the product in its entity, successful or not. Therefore we do not talk about so called mistakes anymore. Thus we avoid getting into argument with each other as the Swiss translator Raffael Keller and the German translator Rainald Simon recently did in a very unpleasant way (Simon 2017). They were only quarreling about the wrongs and rights of words, as if a text would be made up of single characters! Here hate speech has arrived in Chinese Studies!

What we used to regard as faults in the past, we now take as a different form of understanding, a different way of a possibility that a text might offer. See the great translator Franz Kuhn (1884-1961) who is accused of having produced a simple digest of The Dream of the Red Chamber (Hongloumeng, 1792), but in fact did what all German translators of French novels previously did as well as during his times: cutting the novels down according to the demands of the publisher or to the needs of the readership. It is true that he only offers 55 chapters or so of 120 chapters. At the same time, one has to confess that no one can say for sure the original really consisted of 120 chapters, perhaps only of 80 chapters, the second part might have been added by someone else. And even these genuine eighty chapters present us with a lot of deviations from edition to edition.

What is constantly overlooked in translation theory till now is the fact that no book is done by one person alone. In our case the fate of a translation is decided, so it seems, first by the translator, then by the editor, further by the publisher, by the designer, by the agent, finally by the book seller etc. The editor and the publisher have the right to change anything. So what we seem to bring to light, is never our work alone. Many are involved and they might produce so called mistakes indeed. So it is unfair to scold the translator without inquiring what the publishing house did to the manuscript. One is sometimes not even told! Though the critics should know it better, these judges of our undertakings behave not much differently than 
the reader: For them, only the pair of an author and the translator seem to exist, and if something works out wrong way, guess-whose fault will it be then? Of course, it is the translator, who is the only concrete person that can be named and made responsible.

\section{Understanding, communication}

As long as the precondition of translating is understanding, we have now to turn to the problem of epistemology. What we as human beings hope for is a kind of cognition that is valid once and forever: What we recognize today, should still be the same tomorrow as well. Even vice versa. But it is never this way. Any word or character has a long history of its own which is always changing. Any fixed meaning that we can look up in any dictionary is a mere illusion!

What we today translate as "human being/(wo) man", ren 人, never meant something like that in ancient China. Still those in Chinese Studies render it that way according to their dictionaries today. Ren might of course have the meaning of "man" (German: Mensch), but since when? Even today you can find Chinese men on the mainland who frankly tell you: women are not "ren": 女人不是人!(Nüren bu shi ren).

"Man" in the sense of man/Mensch as we use it today is a very recent term. Ancient Greece, ancient India, ancient China do not know it ("Mensch [...])" 1980). There is no clear distinction between "man"and animals, between men and gods. The Chinese character for ren is an expression of rank and refers foremost to a male aristocrat!

Even our European terms are at stake. Around 1789, "les hommes" never included women after the French Revolution! So, there were in fact no human rights demanded for all at that time, there were only rights reserved for men! If we really can start our translating work from the single word, we have to first give up any dictionary! And then? Try to understand! Understand what? The context, the words before and after that single word! Its history, its use, its development!

But what does "understand" stand for here? We now run into our greatest problem, because this verb is rather a late one and as a philosophical term even later, though as such it has theologian forerunners long ago ("Verstehen [...])" 2001). In German it is called "verstehen", it has a root in old German as in old English (Pfeifer ed. 2014, 1510, 1511). In both countries it has only a short history: As a verb, it is not older than about thousand years, as a philosophical term, it begins to grow slowly with Friedrich Schleiermacher (1768-1834), before it gained fundamental importance at the end of the nineteenth century with J. B. G. Droysen (1808-1884) and Wilhelm Dilthey (1833-1911), and in the middle of the twentieth century with Martin Heidegger (1989-1976) and Hans-Georg Gadamer (1900-2002). Since then, it bears the philosophical notion of "Seinskönnen" (able to exist?). It is obvious that what we mean by "understand" today cannot be preponed. That might be even true for Latin intellegere or Greek noein oder gignoskein. The Chinese-American philosopher Tu Wei-ming (Du Weiming, b. 1940) claims an optimistic epistemology for (Neo) Confucianism. But I doubt in 
all three cases that our findings in modernity can be compared to ancient times or even middle ages of any culture. Understanding might not have turned into a real philosophical problem before the discovery of the "other" as opposite to "self". One has to doubt oneself before that, but China has never been a culture of doubt, to the contrary, it offers a culture of confirmation up till now. Even the Chinese Communist Party gives an excellent example for this phenomenon.

According to common etymological reference books "verstehen"/"understand" as a verb has a legal background. It goes back to Latin "perstare" and coined as "durchstehen" in German (to get through?), in the sense of getting through a legal trial. One who is able to dominate a legal case mentally, such a kind of person is said to possess the capability to "understand" any context in life.

Instead of "understanding", Karl Jaspers (1883-1969) speaks of "communication" as universal precondition of being human (Menschsein). With his philosophy of communication this noun became a philosophical term. Long before that it had already been a theological one ("Kommunikation [...]" 1976). It started with Nicolaus Cusanus (1401-1464) who saw exegesis as creating and being created through the announcement (communication) of divine existence (Sein). Communication has Latin communis (common) as its root. Thus, communication means to make something common for everyone. In this simple sense, one can regard "understanding" as the way of translation. Through translation, a text gets "common" for someone whose eyes or ears or mind were closed for a text in a different language.

As any translation work of mankind starts with the act of making common holy scripts through the undertaking of translating, be it in the Occident (Bible) or in China (Buddhist sutras), therefore any secular translation still means as much as making something common that is still under the nimbus of holiness. It is not before the death of poets like Rainer Maria Rilke (1875-1926) that the religious sound nearly disappeared in literature, but it came back with socialist society (Mao Zedong hailed as helmsman). But what does this mean for us translators, especially when we think of translation theory, whose origin is also in theology and its practice is nothing else than exegesis? Just to remind you: Modern translation theory started with the American theologian Eugene A. Nida (1914-2011) (Nida 1964) and is since then a hot issue in Germany (cf. the School of Germersheim/Mainz University) with its nation of translators.

Translation is a kind of thorough exegesis and therefore a kind of communitive act. Just as it is impossible to explain the many languages of the Bible one hundred percent, we cannot guarantee that modern translation of old, modern or contemporary works will get much better off. Of course, we have been enjoying excellent Chinese-German/Chinese-English lexica since about 1985. But do they really support us to find a solution for a binomial like kongshan 空山? In this case, a bilingual dictionary would lead us astray. Kongshan is not an empty mountain, as we can often read. It has plants, birds, insects, air, the sun and sometimes people. The character kong does not describe the mountain, but the observer. It is open regarding its meaning, we have a lot of possibilities to render this Buddhist term for a certain religious (also philosophical) kind of enlightenment. No possible translation can be said to be exclusive or the best one. We are 
free for any decision, but it must be consistent. There will be as many translations as there are translators, because the understandings of all translators will always differ. I myself chose "transparent mountain": Such a mountain allows you to see through it and encounter Buddha at its very end.

\section{Possibilities}

The American literatus Eliot Weinberger (b. 1949) who is himself a translator (of Bei Dao for instance) and who learned some Chinese in his youth has been very successful with his book Nineteen Ways at looking at Wang Wei (1987), be it in the United States or in a German bestseller list (Weinberger 2019). What we get to know through him is that the poem of Wang Wei (699?-759?), which starts with the binomial kongshan, changes with each of its translations by 19 Sinologists and international poets all the time. We cannot expect one and the same text in English or German. It is not only that the translators' translations are different, it is also that their understanding differs a lot. Instead of finding $A$ translated into $A(A=A)$, we are offered $\mathrm{A} \neq \mathrm{A}$, i.e. the translation $\mathrm{A}=\mathrm{A} 1, \mathrm{~A} 2, \mathrm{~A} 3 \ldots \mathrm{A} 19$.

This is why I continue saying a certain translation is only a possibility, one possibility of many possibilities. And the understanding that our translation is based upon is a possibility, too, one of many possibilities. So our critics telling us there is no perfect translation work are right? This question is raised in the wrong way! As long as there is no understanding that all can share, there can only be different forms of expressing our understanding and creations.

Sometimes I am asked by colleagues or students or friends: Please tell me, what is here in the text? Please help me translate. I shall then tell them: There is no single sentence that is clear. So we can never just translate what we see on a sheet of paper. We first have to check the complete text and then decide what might be hit at. Should someone declare: This or that makes sense as A or B, I would add, there still might be something else, something more, C or D. All of us long for a clear and complete understanding and translation. But if there should be something like that, it would come close to the end of understanding, exegesis and translation. We would be like a divine being which does not need explanations and translators at all. As a possibility, understanding and translation never reach a final stage. Otherwise, we would stop interpreting Du Fu (712-770) or stop translating again The Dream of Red Chamber.

Germany is said to be the country of translators. Seventy percent of all books published per year are translations. Not only her translators, but also German sinologists have now turned to translation theory and the problem of understanding. It is not by accident that in 2020 two studies of how to understand China came out about the same time in German (Pohl 2020; Kaminski 2020). ${ }^{1}$

Of course, we do not stand alone. Three decades ago, our colleagues in Hong Kong already tried to come to terms with our topic (Allison, ed. 1989). Their undertaking was of a more practical nature. The emphasis was mainly laid upon the

\footnotetext{
1 The second author is of course Austrian!
} 
object (philosophy) and less upon the verb (understand). The editor recommended two ways: (1) to comprehend China through her understanding of herself, and (2) to approach her, to "get closer", from a "Western" understanding and methodology. In the first case, one could argue from the point of Hans-Georg Gadamer that this would strengthen the Chinese claim: See us the way we see ourselves. It would double (Verdopplung) the Chinese standpoint. In the second case, and as conceded by the editor, one would be accused of cultural Imperialism. Hermeneutics, which slowly started in Germany in 1654 on the foundations of theology and law, would assert that it should be neither nor. Therefore, the issue of understanding has to be kept away from accusations of narcissistic or imperial attitude, because it is a matter of the entirety of our shared human existence ("Hermeneutik" 1974).

Funding Open Access funding enabled and organized by Projekt DEAL.

Conflict of Interest I declare that there is no conflict of interest in the publication of this article, and that there is no conflict of interest with any other author or institution for the publication of this article.

Ethical Statements I hereby declare that this manuscript is the result of my independent creation under the reviewers' comments. Except for the quoted contents, this manuscript does not contain any research achievements that have been published or written by other individuals or groups. I am the only author of this manuscript. The legal responsibility of this statement shall be borne by me.

Data Availability Not applicable.

Code Availability Not applicable.

Author contributors I am the only author.

Open Access This article is licensed under a Creative Commons Attribution 4.0 International License, which permits use, sharing, adaptation, distribution and reproduction in any medium or format, as long as you give appropriate credit to the original author(s) and the source, provide a link to the Creative Commons licence, and indicate if changes were made. The images or other third party material in this article are included in the article's Creative Commons licence, unless indicated otherwise in a credit line to the material. If material is not included in the article's Creative Commons licence and your intended use is not permitted by statutory regulation or exceeds the permitted use, you will need to obtain permission directly from the copyright holder. To view a copy of this licence, visit http://creativecommons.org/licen ses/by/4.0/.

\section{References}

Allison, Robert E., ed. 1989. Understanding the Chinese Mind. The Philosophical Roots. Hong Kong: Oxford University Press.

Hermeneutik. 1974. In Joachim Ritter et al., eds. Historisches Wörterbuch der Philosophie; 3. Darmstadt: Wissenschaftliche Buchgesellschaft, columns 1061-1074.

Kaminski, Gerd. 2020. Der Fremde kennt nicht unsere Wege. Chinaknigge für Langnasen. Schiedlberg: Bacopa.

Kommunikation (lat. communicatio; frz./engl. communication; ital. communicazione). 1976. In Joachim Ritter et al., eds. Historisches Wörterbuch der Philosophie; 4. Darmstadt: Wissenschaftliche Buchgesellschaft, columns 893-896.

Luo, Guangzhong. 2017. Die Drei Reiche. Aus dem Klassischen Chinesisch übersetzt und herausgegeben von [Ed. and trans. by] Eva Schestag. Zwei Bände. Frankfurt: S. Fischer. 
Mensch (griech. á $\nu \theta \rho \omega \pi$ os; lat. Homo; ital. Uomo; frz. Homme; engl. man). 1980. In Joachim Ritter et al., eds. Historisches Wörterbuch der Philosophie; 5. Darmstadt: Wissenschaftliche Buchgesellschaft, columns 1059-1105.

Nida, Eugene A. 1964. Toward a Science of Translating. With Special Reference to Principles and Procedures Involved in Bible Translating. Leiden: Brill.

Pfeifer, Wolfgang. ed. 2014. Etymologisches Wörterbuch des Deutschen. Koblenz: Edition Kramer.

Pohl, Karl-Heinz. 2020. China für Anfänger. Eine faszinierende Welt entdecken. Bochum: Europäischer Universitätsverlag.

Simon, Rainald. 2017. St. Gallener Chinoiserien im jambischen Ärmelkleid. In Julietta Fix, ed. (n.d.). Fixpoetry. Wir reden über Literatur. https://www.fixpoetry.com/feuilleton/kritiken/raffael-keller/ neunzehn-gedichte-aus-alter-zeit-gushi-shijiu-shou. Accessed 20 Aug 2020.

Verstehen (engl. to understand, understanding bzw. to comprehend, comprehension; frz. comprendre, comprehension; ital. Comprendere, comprensione). 2001. In Joachim Ritter et al, eds. Historisches Wörterbuch der Philosophie; 11. Darmstadt: Wissenschaftliche Buchgesellschaft, columns 918-938.

Weinberger, Eliot. 2019. 19 Arten Wang Wei zu betrachten. Hg. und übers. von [Ed. and trans. by] Beatrice Faßbender. Berlin: Berenberg.

Wort (engl. word; frz. mot). 2004. In Joachim Ritter et al., eds. Historisches Wörterbuch der Philosophie; 12. Darmstadt: Wissenschaftliche Buchgesellschaft, columns 1023-1036. 